\title{
An Experimental Investigation of Mechanical Properties of Bonded Concrete
}

\author{
F. M. Tehrani
}

\begin{abstract}
This paper presents an experimental study to measure mechanical properties of bonded concrete specimens. The bond between freshly mixed and hardened concrete has been a concern in repair and retrofit projects as well as staged construction of concrete members. This concern has roots in the time-dependent behavior of concrete, beginning with earlyage concrete and continuing with long-term performance and durability of concrete. Moreover, environmental conditions generally complicate the behavior of concrete and resulted deformations such as shrinkage and creep. Application of chemical adhesives and epoxies is a common technique to enhance the bond at the interface of old and new concrete elements. The presented methodology includes preparation of bonded specimens with application of grout and adhesive agents. Mechanical strengths of specimens have been reported based on compressive, tensile, flexural, and shear testing. Results indicate that bonding agents are more effective in tensile and shear behavior of bonded samples.
\end{abstract}

Index Terms — adhesives, bonding, grouting.

\section{INTRODUCTION}

Bonding between freshly mixed and hardened concrete is a major concern in repair, retrofit, and strengthening projects, as well as new projects with staged construction. These projects are often necessary due to poor design, problems in construction, or inadequate maintenance of structures. The time-dependent behavior of concrete is a bonding concern when delays are present in the process of concrete placement, disregarding the intentional or incidental nature of the delay. Moreover, changes in occupancy, environmental and loading conditions, and extended use of structures may also warrant repair or retrofit which requires bonding new and old concrete elements [1][3].

The general objective of concrete repair is to re-instate the properties of damaged element in respect to service, strength, and durability. Similarly, strengthening aims to enhance the properties of existing members with the aid of new materials. In these areas, the load transfers between new and old concrete through their interface, where bonded properly, as well as reinforcing dowels, where embedded adequately. Thus, bonding, either between freshly mixed and hardened concrete or between concrete and reinforcing bars is an essential factor in securing the load transfer. In plain concrete, the interfacial bonding is practically the only resisting force against cracking, as frictional resistances are generally accompanied with relative sliding movements. In addition, placement of dowels and anchored reinforcing bars is cost-prohibitive for plain concrete applications, and nonconstructible in case of incidental delays in concrete placement. Thus, developing interfacial bond might be the preferred option for most applications. It should be noted that repair and retrofit projects, when executed properly, are cost effective solutions in comparison to a demolish-andrebuild alternative for concrete structures [4]-[5].

Performance measures of repairing materials generally include:
a. Adhesion
b. Thermal deformations
c. Permeability
d. Protecting embedded steel components
e. Mechanical strengths
f. Ease of application
g. Thaw and freeze cycling strength
h. Chemical resistance.

Environmental and loading conditions further influence the criteria for selecting materials and methods of the repair. The method of repair, such as injection, cast-in-place, and shotcrete, impose additional requirements for the selection of materials [6]. Furthermore, application of fiberreinforcement [7]-[11], recycled materials [12]-[16], and manufactured lightweight aggregates [17]-[19] interact with decision making procedures to determine the appropriate materials in respect to sustainability performance measures such as cost, energy, and emissions throughout the service life of the infrastructure [20]-[22].

Conventional concrete is the most basic repair material, particularly for large-volume applications. Mortars and pastes can similarly cover thin applications. However, the shrinkage of the fresh cementitious mix requires special treatment to avoid immediate cracks at the interface between new and old concrete elements. There are numerous additives, polymers, and resins to treat this problem by shrinkage compensating expansion of the concrete. However, focused treatment of the interface by epoxies and adhesives is often an economic solution for large volume applications [23], [24].

This paper focuses on mechanical strengths of bonded specimens with application of selected adhesives and epoxies. The objective of this paper is to present a methodology to measure the mechanical performance of bonded specimens for any general bonding agent. Results provide insights on expected performance of these bonding agents. 


\section{METHODOLOGY}

\section{A. Materials}

The selected mix design for concrete samples included $350 \mathrm{~kg}$ of cement per cubic meter of concrete, with the water-cement-ratio of 0.5 . The result of slump test was 45 $\mathrm{mm}$. The selected adhesive was a commercial silicone-based adhesive added to the mixing water of concrete at 1-1 volumetric ratio. The selected grout was a commercial nonshrink grout (Fig. 1).

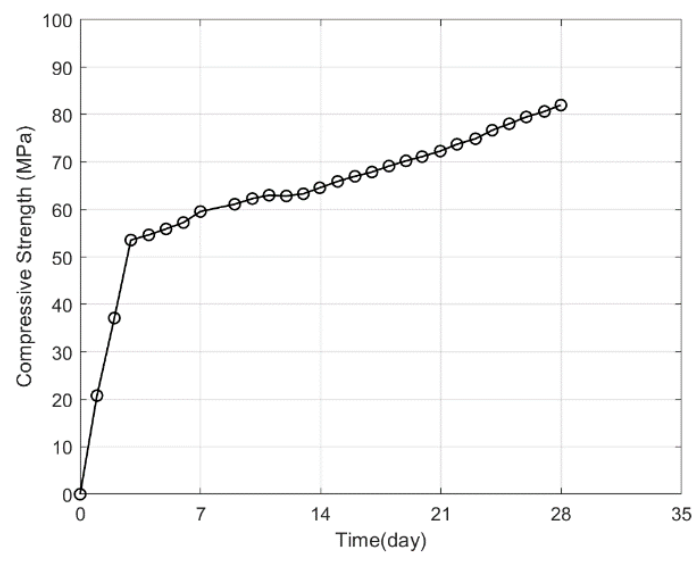

Fig. 1. Compressive Strength of the Grout.

\section{B. Preparation of Specimens}

Experimental investigations included three groups of specimens:

a. Witness specimens (group A): These samples were cast with plain concrete in one piece for comparison purposes.

b. Bonded specimens with plain concrete (group B): These samples were bonded with plain concrete without any adhesive or grout.

c. Bonded specimens with bonding agents (group C): These samples were bonded with selected adhesive or grout.

Two methods of repair were studied in these experimentations:

a. Interface method (method 1): Plain concrete (group A) was placed in half of the concrete mold and cured properly. Then, the second half was filled with new concrete and curing was repeated for the second half. This method resulted in an interface with zero thickness between old and new concrete (Fig. 2).
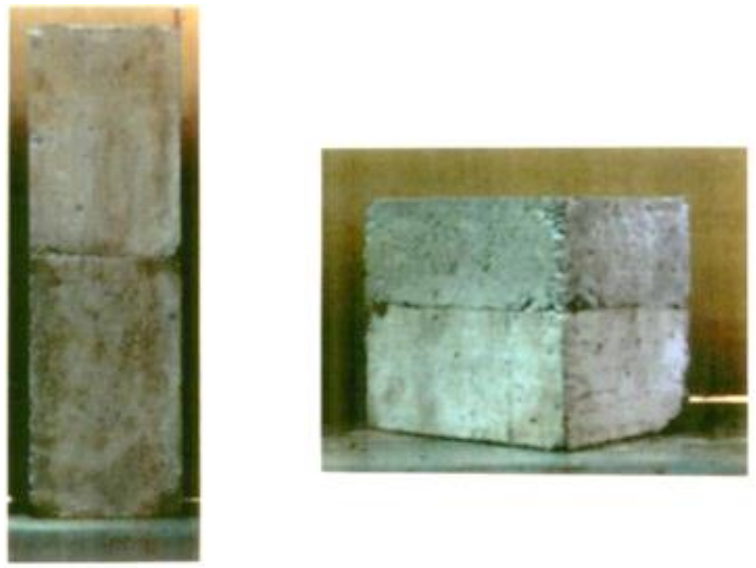

Fig. 2. Bonding Interface between New and Old Concrete. b. Joint method (method 2): The entire mold was filled with plain concrete (group A), except for a 10-mm gap at the middle of the mold. After initial curing, the gap was filled with repair materials (Fig. 3).

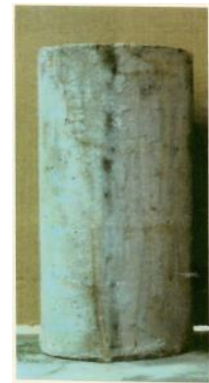

Fig. 3. Repaired Longitudinal Gap between New and Old Concrete.

Table 1 lists specimen groups, repair methods, and their descriptions. All specimens were steam cured. In addition, selected witness samples (group A) were cured with water for comparison purposes. This comparison indicated that steam-cured specimens gained $95 \%$ of the 7-day strength of water-cured specimens. Regardless, the evaluation of results is based on comparison between relative strength of specimens to the strength of the witness sample. Thus, conclusions are independent of common preparation and curing techniques.

TABLE I: COMPRESSIVE STRENGTH RESULTS

\begin{tabular}{cc}
\hline \hline Specimen Group & Description of Repair Method \\
\hline A & Witness \\
B-1 & Jointed Concrete \\
B-2 & Grouted Jointed Concrete \\
C-2 & Grouted Jointed Concrete with Adhesive \\
\hline
\end{tabular}

\section{Testing}

Specimens were tested for following measures:

a. Compressive strength [25]: Standard cube $(150 \mathrm{~mm})$ samples of each specimen group were tested for compressive strength. The load was applied perpendicular to bonding interface and joint (Fig. 4).
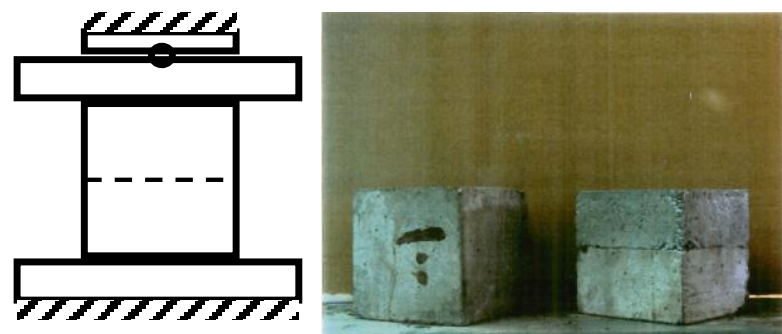

Fig. 4. Location of Bonding Interface/Joint (dashed line) in the Compression Test Setup.

b. Flexural strength [26]: Four-point-loading standard samples $(150 \times 150 \times 500 \mathrm{~mm})$ were tested on $450 \mathrm{~mm}$ span loaded at $150 \mathrm{~mm}$ spacing for flexural strength. Bonding interface and joint were placed at the middle segment of the beam, parallel to the loading system (Fig. 5).

c. Tensile strength [27]: standard cylindrical $(150$ x 300 $\mathrm{mm}$ ) samples of each specimen group were tested for splitting tensile strength. Bonding interface and joint were oriented parallel to both loading system and longitudinal direction of specimens (Fig. 6). 

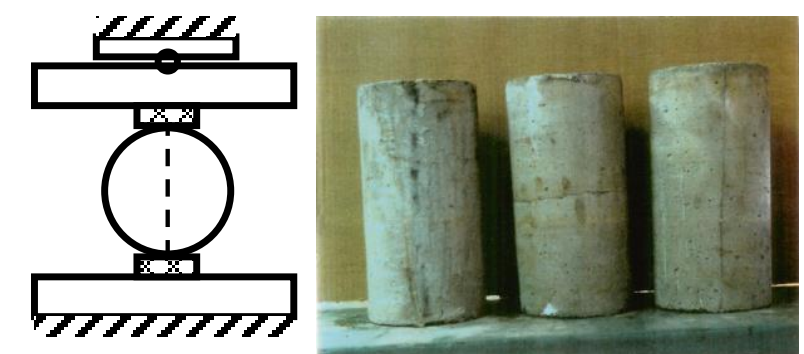

Fig. 5. Location of Bonding Interface/Joint (dashed line) in the Splitting Tensile Test Setup.
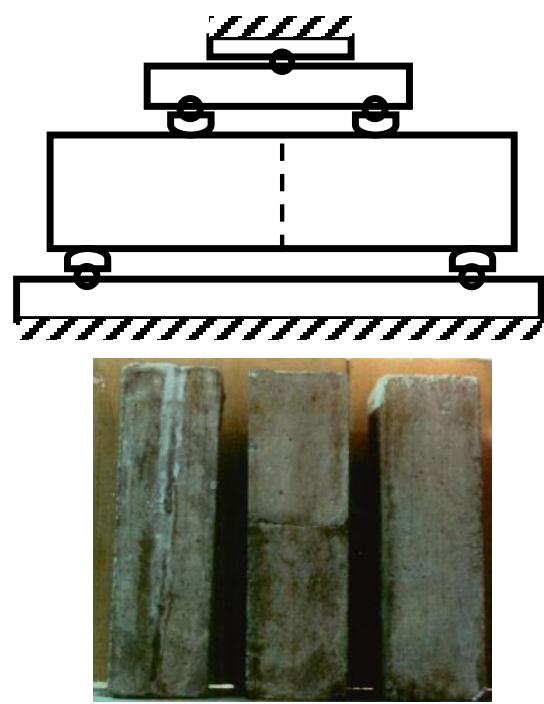

Fig. 6. Location of Bonding Interface/Joint (dashed line) in the Flexural Test Setup.

d. Shear strength: Cube $(150 \mathrm{~mm})$ samples of each specimen group were loaded at different angles to measure the shear strength (Fig. 7).

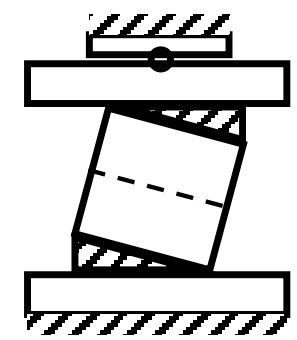

Fig. 7. Location of Bonding Interface/Joint (dashed line) in the Shear Test Setup.

\section{RESULTS}

\section{A. Compressive Strength}

Table 2 shows the average result of compression tests on selected specimens. Observations indicate that all repaired samples showed a reduction in strength in comparison with the uniformly casted witness sample. However, application of adhesive and grout together partially compensated this reduction.

TABLE 2: COMPRESSIVE STRENGTH RESULTS

\begin{tabular}{ccc}
\hline \hline $\begin{array}{c}\text { Specimen } \\
\text { Group }\end{array}$ & $\begin{array}{c}\text { Compressive Strength } \\
(\mathrm{MPa})\end{array}$ & $\begin{array}{c}\text { Relative strength to witness } \\
\text { sample (\%) }\end{array}$ \\
\hline A & 26.6 & 100 \\
B-1 & 15.3 & 57.4 \\
B-2 & 15.8 & 59.4 \\
C-2 & 20.7 & 77.9 \\
\hline \hline
\end{tabular}

\section{B. Flexural Strength}

Table 3 shows the average result of flexural tests on selected specimens. While the strength of jointed specimen was negligible, the grouted specimen showed the same strength as of the witness sample.

TABLE 3: FLEXURAL STRENGTH RESULTS

\begin{tabular}{ccc}
\hline \hline $\begin{array}{c}\text { Specimen } \\
\text { Group }\end{array}$ & $\begin{array}{c}\text { Flexural Strength } \\
(\mathrm{MPa})\end{array}$ & $\begin{array}{c}\text { Relative strength to witness } \\
\text { sample }(\%)\end{array}$ \\
\hline A & 1.3 & 100 \\
B-1 & Negligible & Negligible \\
B-2 & 1.3 & 100 \\
\hline \hline
\end{tabular}

\section{Tensile Strength}

Table 4 shows the average result of split-tensile tests on selected specimens. The advantage of using grout in repairing cracks is well presented in these results, where the strength of grouted specimen has exceeded the strength of the witness sample.

TABLE 4: TENSILE STRENGTH RESUlTS

\begin{tabular}{ccc}
\hline \hline $\begin{array}{c}\text { Specimen } \\
\text { Group }\end{array}$ & $\begin{array}{c}\text { Tensile Strength } \\
\text { (MPa) }\end{array}$ & $\begin{array}{c}\text { Relative strength to witness } \\
\text { sample }(\%)\end{array}$ \\
\hline A & 1.04 & 100 \\
B-1 & 0.69 & 66.6 \\
B-2 & 1.46 & 140 \\
C-2 & 1.60 & 153 \\
\hline \hline
\end{tabular}

\section{Shear Strength}

Table 5 shows the average result of shear tests on selected specimens. Reported strength values combine compression and shear loads at given angles, i.e. $10 \%, 20 \%$, and $30 \%$. The resulted shear strength for grouted specimens have exceeded the strength of witness sample for all angles. Presence of compressive stresses in these tests allows inclusion of friction forces to be considered in the overall shear strength values. Observations indicate that grouted specimens gained $20 \%$ to $30 \%$ extra strength in shear.

TABLE 5: SHEAR STRENGTH RESULTS

\begin{tabular}{ccccccc}
\hline \hline Specimen Group & \multicolumn{3}{c}{ Compressive Strength (MPa) } & \multicolumn{3}{c}{ Shear Strength (MPa) } \\
\hline Angle & $10 \%$ & $20 \%$ & $30 \%$ & $10 \%$ & $20 \%$ & $30 \%$ \\
A & 1.66 & 1.44 & 1.32 & 0.17 & 0.29 & 0.39 \\
B-1 & 1.46 & 1.35 & 1.22 & 0.15 & 0.27 & 0.37 \\
B-2 & 2.15 & 1.92 & 1.88 & 0.21 & 0.39 & 0.56 \\
C-2 & 2.05 & 1.73 & 1.50 & 0.20 & 0.35 & 0.45 \\
\hline \hline
\end{tabular}

\section{CONCLUSION}

Fig. 8 provides a comparison between mechanical properties of various specimen groups and repair methods. This figure indicates that presence of joints has reduced the strength of all specimens. Application of grout has had a positive influence on the strength of repaired specimen for all tests. Application of adhesives in addition to grout has not necessarily enhanced the strength further. Repair methods have been highly influential in tensile and shear tests.

Concluding results indicate the effectiveness of the proposed methodology in assessing repair methods and materials. However, the number of specimens is not large enough to allow reliable conclusions on the appropriateness 
of applied methods and materials. Practitioners should consider proper testing programs before specifying any method or material of concrete repair.

틀 틀 $\mathrm{B}-1$ 를-2 틀 C-2

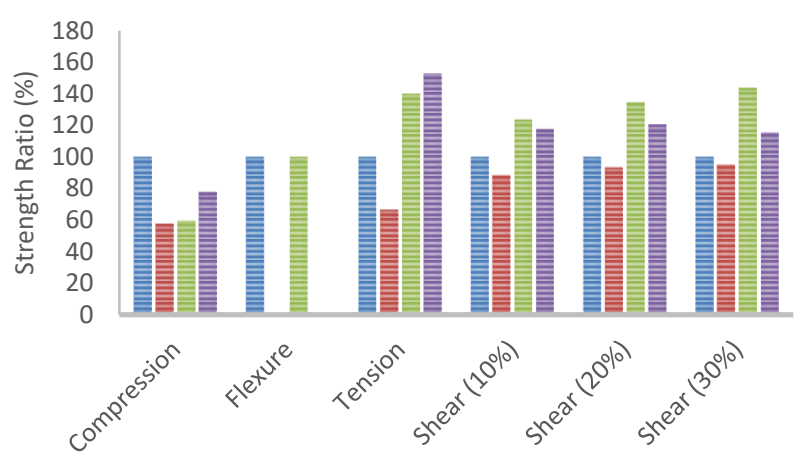

Fig. 8. Strength Ratio for Various Specimens and Repair Methods

\section{ACKNOWLEDGMENT}

Presented experimental investigations have been carried out in the BCRC laboratories.

\section{REFERENCES}

[1] FIP (Fédération International de la Précontrainte) Commission on Practical Construction. Repair and strengthening of concrete structure, London: Thomas Telford, 1991.

[2] ACI (American Concrete Institute) Committee 503. Guide for the selection of polymer adhesives with concrete, ACI 503.5R-92. Detroit, MI: American Concrete Institute, 1992.

[3] Knab L., and C. B. Spring. "Evaluation of test methods for measuring the bond strength of Portland-cement based repair material to concrete," Cement, Concrete and Aggregate, vol. 11, no. 1, pp. 3-14, 1989.

[4] Rizzo, E. M., and M. B. Sobelman. "Selection criteria for concrete repair material," Concrete International, vol. 11, no. 9, pp.46-49, 1989.

[5] Tracy, R. G., and R. S. Fling. "Rehabilitation strategies," Concrete International, vol. 11, no. 9, pp.41-45, 1989.

[6] ACI (American Concrete Institute) Committee 548. Guide for the application of epoxy and latex adhesives for bonding freshly mixed and hardened concretes, ACI 548.11R-12. Farmington Hills, MI: American Concrete Institute, 2012.

[7] Tehrani, F. M. "Performance of Steel Fiber Reinforced Concrete in Beam-Column Connections," Ph.D. dissertation, Dept. Civil and Environmental Engineering, University of California, Los Angeles, CA, 2008.

[8] Tehrani, F. M., and R. M. Serrano. "Crack Propagation of Concrete Ties Prestressed with Single Strand Tendons," Journal of Civil Engineering Research, vol. 4, no. 3, pp. 71-81, 2014.

[9] McComb, C., and F. M. Tehrani. "Enhancement of Shear Transfer in Composite Deck with Mechanical Fasteners," Journal of Engineering Structures, vol. 88, no. 1, pp. 251-261, 2015.

[10] Shadravan, B., and F. M. Tehrani. "A Review of Direct Shear Testing Configurations for Bond between Fiber-Reinforced Polymer Sheets on Concrete and Masonry Substrates," Periodica Polytechnica Civil Engineering, vol. 61, no. 4, pp. 740-751, 2017.

[11] Soto, A., and F. M. Tehrani. "Investigation of Crack Propagation in Steel-Concrete Composite Beams using Fiber Reinforcement," Periodica Polytechnica Civil Engineering, vol. 62, no. 4, pp. 956-962, 2018.

[12] Miller, N. M., and F. M. Tehrani. "Mechanical Properties of Rubberized Lightweight Aggregate Concrete," Journal of Construction and Building Materials, vol. 147, no. 30, pp. 264-271, 2017.

[13] Tehrani, F. M., and N. M. Miller. "Tire-derived Aggregate Cementitious Materials: A Review of Mechanical Properties," in Cement-based Materials, Ed. by H. Saleh. London, UK: IntechOpen, 2018.
[14] Tehrani, F. M., J. Carreon, and N. Miller. "An Investigation of Tirederived Lightweight Aggregate Concrete," in ACI Special Publication SP-334-5, Ed. by ACI Committee 555, no. 334, pp. 68-98, 2019.

[15] Nazari, M., F. M. Tehrani, M. Ansari, B. Jeevanlal, F. Rahman, and R. Farshidpour. "Green Strategies for Design and Construction of Non-Auto Transportation Infrastructure," Report 19-17, San Jose, CA: Mineta Transportation Institute, 2019.

[16] Tehrani, F. M., M. Nazari, D. Truong, and R. Farshidpour. "Sustainability of Tire-Derived Aggregate Concrete: A Case Study on Energy, Emissions, Economy, and ENVISION," Proc. International Conference on Sustainable Infrastructure 2019: Leading Resilient Communities through the 21st Century, Los Angeles, CA: ASCE, (November 6-9, 2019), pp. 399-408, 2019.

[17] Tehrani, F. M. Rāhnamā-ye Jāme'-e Lìkāa, [The Comprehensive Guide to LECA, in Persian], New Edition, Tehran, Iran: Omīdān 2010.

[18] Tehrani, F. M., R. Farshidpour, M. Pouramini, M. Mousavi, and A. N. Esfahani. "Sustainability Rating of Lightweight Expanded Clay Aggregates using Energy Inputs and Carbon Dioxide Emissions in Life-cycle Analysis," The Sixth International Symposium on Life Cycle Civil Engineering, Ghent, Belgium: IALCCE, (October 2018), pp. 2989-2993, 2018.

[19] Tehrani, F. M. 2019. Notes on Fiber-Reinforced LightweightAggregate Structural Concrete and Concrete Masonry, ESCSI ENewsletter, September 2019.

[20] Tehrani, F. M. 2019. Deploying and Rating Sustainable Practices for Resilient Bridge Infrastructure. Keynote Lecture, Proc. The Fifth International Conference on Bridges, Tehran, Iran: Amirkabir University of Technology. (December 17-18, 2019): MS05.

[21] Bonyadian, S., M. Mohammadi, B. Foroutanmehr, and F. M. Tehrani. "An Experimental Investigation of Internally-Cured Concrete Application for Bridge Decks," The Fifth International Conference on Bridges, Amirkabir University of Technology, Tehran. (December 17-18, 2019), no. MS02, 2019.

[22] Tehrani, F. M. 2020. Service Life Prediction of Structural Lightweight Concrete Using Transport Properties. ESCSI Report 4363, October 2020, Chicago, IL: Expanded Shale, Clay and Slate Institute.

[23] Santos, P. M. D., and E. N. B. S. Júlio. "Factors affecting bond between new and old concrete," ACI Materials Journal, vol. 108, no. 4, pp. 449-456, 2011.

[24] Austin, S., P. Robins, and Y. Pan, "Shear Bond Testing of Concrete Repairs," Cement and Concrete Research, vol. 29, no. 7, pp. 1067 1076, 1999.

[25] ASTM (American Society for Testing and Materials) C39 / C39M17b. Standard Test Method for Compressive Strength of Cylindrical Concrete Specimens, West Conshohocken, PA: ASTM International, 2017.

[26] ASTM (American Society for Testing and Materials) C78 / C78M-16. Standard Test Method for Flexural Strength of Concrete (Using Simple Beam with Third-Point Loading), West Conshohocken, PA: ASTM International, 2016

[27] ASTM (American Society for Testing and Materials) C496 / C496M11. Standard Test Method for Splitting Tensile Strength of Cylindrical Concrete Specimens, West Conshohocken, PA: ASTM International, 2004.

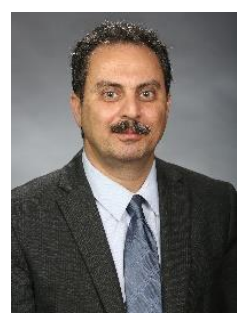

Fariborz M. Tehrani, PhD, PE, ENV SP, PMP, SAP, F.ASCE received Ph.D. (2008), Degree of Engineer (2003), and MS (2002) in civil engineering, University of California, Los Angeles; MSc in Soil Mechanics and Foundation Engineering, Amirkabir University of Technology, Tehran, 1993; and BSc in Civil Engineering, Sharif University of Technology, Tehran, 1990.

$\mathrm{He}$ is an Associate Professor in California State University, Fresno, and the Director of the Expanded Shale, Clay and Slate Institute (ESCSI). He has contributed to publication of 10 books and 70 papers, and dissemination of 90 presentations. His research interests include sustainable and resilient structural engineering, mechanics, and materials (SR-SEMM).

Dr. Tehrani is a Fellow ASCE, past chair of ISI Academic Committee, voting member of numerous ASTM C09, C12, C15, D04, D18, and AC 213, 301-0G, and EAC Committees, and professional member of SEI, EMI, EWB, and ISSMGE. Dr. Tehrani received the ASCE Region 9 Outstanding Faculty Advisor Award in 2015 for leading the Student Chapter from 2010 to 2015, the Best Practice Award from California Higher Education Sustainability Conference in 2017, and the best Research Award from ASCE Fresno and San Francisco for two projects in 2019. 